\title{
Evapotranspiration Rates of Eleven Zoysia Genotypes
}

\section{R.L. Green, S.I. Sifers, C.E. Atkins, and J.B. Beard Department of Soil and Crop Sciences, Texas A\&M University, College Station, TX 77843-2474}

Additional index words. Zoysia japonica, Z. tenuifolia, Z. matrella, leaf extension rate, mowing frequency, shoot density, stomata] density

\begin{abstract}
We compared evapotranspiration (ET) rates for 11 Zoysia genotypes, encompassing two species and their hybrid, maintained at nonlimiting soil moisture under field conditions and in an environmental chamber of high evaporative potential. ET rate relationships to leaf area [leaf extension rate (LER)], canopy resistance [shoot density (SHD)], and internal resistance [abaxial (AB) and adaxial (AD) leaf blade stomatal densities] characteristics were determined. Three-year ET rate means were not significantly different among genotypes in the field study, but ET rates among genotypes differed significantly under the higher evaporative potential of an environmental-chamber study. ET rate was not significantly correlated with LER for either the data from the field or the chamber. ET rates of both types of tests also were not significantly correlated with SHD or AB or AD leaf blade stomatal density. Data from field and environmental-chamber research suggest that differences of individual morphological traits among the 11 zoysiagrasses do not influence the ET rate when measured from minilysimeters maintained at nonlimiting soil moisture.
\end{abstract}

As zoysiagrasses (Zoysia spp.) receive more attention by turfgrass breeders, a need arises for intraspecific evapotranspiration (ET) rate comparisons (Beard, 1973). ET rate may vary as much among cultivars within species as among species (Beard, 1985, 1989). Differences in ET rates have been reported among cool-season grasses (Aronson et al., 1987; Green et al., 1990) and among cultivars of Kentucky bluegrass (Pea pratensis L.) (Shearman, 1986), tall fescue (Festuca arundinacea Schreb.) (Kopec et al., 1988), and perennial ryegrass (Lolium perenne L.) (Shearman, 1989). Differences in ET rates have been reported for two zoysiagrasses (Kim and Beard, 1988).

The primary objective of this research was to compare ET rates for 11 Zoysia genotypes, encompassing two species and their hybrid and having an array of canopy densities and leaf extension rates. The grasses were maintained at nonlimiting soil moisture and evaluated under both field and environmental-chamber conditions of high evaporative potential. A secondary objective was to correlate ET rate to a leaf area characteristic [leaf extension rate (LER)], to a canopy resistance characteristic [shoot density (SHD)], and to internal resistance characteristics [abaxial $(\mathrm{AB})$ and adaxial (AD) leaf blade stomatal densities].

The 11 Zoysia genotypes characterized in

\footnotetext{
Received. for publication 6 Apr. 1990. Texas Agr. Expt. Sta., Journal Article no. TA 25285. A major portion of this investigation has been made possible by a grant from the U.S. Golf Assn. Green Section. Acknowledgement is given to M.C. Engelke, Texas Agr. Expt. Sta., Dallas, for providing plant material. The cost of publishing this paper was defrayed in part by the payment of page charges. Under postal regulations, this paper therefore must be hereby marked advertisement solely to indicate this fact.
}

this study were: Z. japonica Steud. 'Belair', 'El Toro', 'KLS-05', 'KLS-11', 'KLS-13', 'Korean Common', 'Meyer', and '41-21-5'; $Z$. japonica Steud. $\times Z$ Z. tenuifolia Wind. ex Trin. 'Emerald'; and Z. matrella (L.) Merr. 'FC-13521' and 'PI 231146'. Three 210-mmdiameter plugs of turf (replications) per genotype were harvested from their respective mature field plots at the Turfgrass Field Research Laboratory, Texas A\&M Univ., College Station, in May 1985. The root system was severed $5 \mathrm{~mm}$ below the top of the thatch layer and the turf plugs were washed to remove the soil. The turf plugs were individually transplanted onto a growth medium of fritted clay (Van Bavel et al., 1978) contained in black plastic minilysimeter pots (Johns et al., 1983) that were $210 \mathrm{~mm}$ in diameter and $210 \mathrm{~mm}$ deep. Turfs were established in a glasshouse at a range of 35 to 24C. Turfs were mowed weekly at a 51-mm cutting height using a reel mower with clippings removed and were fertilized biweekly with a nutrient solution $(20.0 \mathrm{~N}-8.8 \mathrm{P}-16.6 \mathrm{~K}$ plus micronutrients) at $4.9 \mathrm{~g} \mathrm{~N} / \mathrm{m}$ ' per month. Turfs were maintained under nonlimiting soil moisture conditions, about $-0.01 \mathrm{MPa}$, for the duration of field and chamber studies.

The field portion of the study was initiated following a 4-month establishment phase, when the turf canopies were considered representative of field-grown turf. Field assessments were conducted in Fall 1985, Summer 1986, and Summer 1987. The turfed minilysimeters were maintained in the field during May through October and in the glasshouse during November through April. They received $4.9 \mathrm{~g} \mathrm{~N} / \mathrm{m}^{2}$ per month as a granular nitrogen fertilizer $(21.0 \mathrm{~N}-0.0 \mathrm{P}-$ $0.0 \mathrm{~K})$ when in the field and as a nutrient solution $(20.0 \mathrm{~N}-8.8 \mathrm{P}-16.6 \mathrm{~K}$ plus micronutrients) when in the glasshouse. Mowing was by a reel mower at a cutting height of 51 $\mathrm{mm}$ in 1985 and $25 \mathrm{~mm}$ in 1986 and 1987, with clippings removed. Turf canopies were representative of well-maintained field-grown turf for the duration of the field study. There was no thinning of shoots or visible disease or insect problems.

ET rates and LER were determined for three periods (subsamples) during each year using the water balance method with minilysimeters placed on a site that had been specially constructed as a contiguous field-plot area, as described by Kim and Beard (1988). Exceptions to this methodology were: a) daily ET rates were determined between the 24th and 48th $\mathrm{h}$ following mowing and saturation with water and $b$ ) LER was determined during the $48 \mathrm{~h}$ following mowing and saturation with water and then converted to a 24$h$ basis. There were no visual leaf water stress symptoms during ET rate evaluations, Daily maximum and minimum air temperatures 1.5 $\mathrm{m}$ above the soil surface, pan evaporation, and wind speed at $0.3 \mathrm{~m}$ above the soil surface were measured at the Texas A\&M Experiment Station (TAES) class A National Weather Service Station, located $82 \mathrm{~m}$ from the ET experimental site, during ET rate measurements (Table 1).

Analysis of variance (ANOVA) was made on yearly ET rate and LER subsample means using a randomized complete block (RCB) design and overall years in a repeated-measures design, with genotypes as main plots and years as the repeated-measures factor. Correlations between ET rate and LER were made on genotype means for individual years and overall years (3-year genotype means).

A controlled-environment chamber study was conducted during Summer 1988 to assess the genotypes under conditions of high evaporative potential. The same turfed minilysimeters used in the field study were maintained under a glasshouse cultural regime as described previously, except for a 32-mm cutting height. The canopies were representative of field-grown turf. ET rate and LER were determined in a controlledenvironment chamber described by Johns et al. (1983). The chamber was modified to accommodate 12 minilysimeters in two rows of six on a wooden base. Photoperiod was $14 \mathrm{~h}$ with a chamber-wide average photosynthetic photon flux (PPF) of 1000 $\mu \mathrm{mol} \cdot \mathrm{s}^{-1} \cdot \mathrm{m}^{-2}$, a constant $30 \mathrm{C}$ day and night, daytime dewpoint of $17 \mathrm{C} \quad(\approx 45 \%$ relative humidity), and a wind speed chamber-wide average of $0.65 \mathrm{~m} \cdot \mathrm{s}^{-1}$, measured $20 \mathrm{~mm}$ above the turf canopy. Turfs were acclimated in the chamber, under the same conditions, for 5 days before initiation of ET rate and LER measurements. ET rate for 24 $\mathrm{h}$ and LER for $48 \mathrm{~h}$ were determined three sequential times (subsamples) for each minilysimeter using the method employed in the field studies. Each ET rate subsample was measured at a different chamber location. Each of three complete blocks was a separate run. No leaf wilting or rolling occurred during the chamber study. A visual inspection following completion of the study indicated no restricted rooting at the bottom or sides of the minilysimeters. 
Table 1. Average daily environmental measurements taken during field evapotranspiration rate evaluations for 3 years.

\begin{tabular}{|c|c|c|c|c|c|c|c|c|c|c|}
\hline \multirow[b]{3}{*}{ Year ${ }^{2}$} & \multicolumn{4}{|c|}{ Air temp } & \multirow{2}{*}{\multicolumn{2}{|c|}{$\begin{array}{c}\text { Pan } \\
\text { evaporation } \\
\left(\mathrm{mm} \cdot \mathrm{day}^{-1}\right)\end{array}$}} & \multirow{2}{*}{\multicolumn{2}{|c|}{$\begin{array}{l}\text { Wind } \\
\text { speed } \\
\left(\mathrm{m} \cdot \mathrm{s}^{-1}\right)^{x}\end{array}$}} & \multirow{2}{*}{\multicolumn{2}{|c|}{$\begin{array}{l}\text { Photoperiod } \\
\text { (h) }\end{array}$}} \\
\hline & \multicolumn{2}{|c|}{$\begin{array}{c}\text { Maximum } \\
\left({ }^{\circ} \mathrm{C}\right)^{\mathrm{y}}\end{array}$} & \multicolumn{2}{|c|}{$\begin{array}{l}\text { Minimum } \\
\left({ }^{\circ} \mathrm{C}\right)^{y}\end{array}$} & & & & & & \\
\hline & $\overline{\bar{x}}$ & $\overline{S E}$ & $\overline{\bar{x}}$ & SE & $\overline{\mathrm{x}}$ & $\overline{\mathrm{SE}}$ & $\overline{\bar{x}}$ & $\overline{S E}$ & $\overline{\bar{X}}$ & $\mathrm{SE}$ \\
\hline 1985 & $31.6^{w}$ & 1.1 & $17.2^{\mathrm{w}}$ & 1.4 & $8.5^{w}$ & 0.5 & $2.9^{\mathrm{w}}$ & 0.3 & 11.88 & 0.04 \\
\hline 1986 & 34.3 & 1.3 & 22.0 & 0.2 & 8.8 & 0.8 & 0.4 & 0.1 & 13.76 & 0.02 \\
\hline 1987 & 24.6 & 1.0 & 7.2 & 1.2 & 6.1 & 0.4 & 3.2 & 0.4 & 11.17 & 0.05 \\
\hline
\end{tabular}

${ }^{2}$ Sept. 1985, July 1986, Oct. 1987.

yMaximum and minimum air temperatures measured $1.5 \mathrm{~m}$ above soil surface.

*Wind speed measured $0.3 \mathrm{~m}$ above soil surface.

"Mcans are the average of 6 days ( 2 days per ET rate subsample $\times$ three subsamples) measured for $24 \mathrm{~h}$ at the TAES class A National Weather Service Station located $82 \mathrm{~m}$ from the experimental site.

Table 2. Evapotranspiration rates for 11 zoysiagrass genotypes under field conditions.

\begin{tabular}{lcccc}
\hline \hline & \multicolumn{4}{c}{ ET rate $\left(\mathrm{mm} \cdot\right.$ day $\left.^{-1}\right)$} \\
\cline { 2 - 5 } Genotype & 1985 & 1986 & 1987 & Overall \\
\hline Belair & 4.1 & 4.8 & 2.5 & 3.8 \\
FC-13521 & 4.1 & 5.0 & 2.5 & 3.8 \\
Emerald & 4.0 & 4.7 & 2.9 & 3.9 \\
El Toro & 4.1 & 4.9 & 2.8 & 3.9 \\
KLS-05 & 4.1 & 4.6 & 3.4 & 4.0 \\
KLS-13 & 4.2 & 4.6 & 3.3 & 4.0 \\
Korean Common & 4.2 & 5.1 & 2.9 & 4.1 \\
PI 231146 & 4.1 & 4.7 & 3.7 & 4.2 \\
Meyer & 5.2 & 5.3 & 2.7 & 4.4 \\
41-21-5 & 4.6 & 5.2 & 3.8 & 4.5 \\
KLS-11 & 4.9 & 5.5 & 3.6 & 4.7 \\
$\quad$ LSD & $\mathrm{NS}$ & $\mathrm{NS}$ & 0.7 & $\mathrm{NS}$ \\
Mean & 4.3 & 4.9 & 3.1 & 4.1 \\
CV (\%) & 13.8 & 13.3 & 13.0 & 13.0 \\
\hline
\end{tabular}

${ }^{\mathrm{NS}}$ Genotype effect not significant.

After completion of the ET rate and LER determinations, polyvinyl leaf blade impressions were made of both $\mathrm{AB}$ and $\mathrm{AD}$ sides (Rice et al., 1979). Only second and third youngest fully expanded leaf blades were used. Stomates were counted at $\times 400$ using four $\mathrm{AB}$ and four $\mathrm{AD}$ leaf blade impressions from each minilysimeter; eight areas, each $0.06 \mathrm{~mm}^{2}$, were counted from the midportion of each leaf blade impression. Counts were converted to a square-millimeter-density basis. The number of live shoots was counted in a frame $(50 \times 100 \mathrm{~mm})$; counts were converted to a per square-decimeter basis.

ANOVA was conducted on subsample means for each dependent variable using a $\mathrm{RCB}$ design. Correlations on genotype means were made between variables. Correlation coefficients also were calculated between 3year genotype means of the field study and genotype means of the environmental-chamber study. It appeared that the chamber environment was characterized by greater genotypic variation for ET rate than the field environment. Thus, the ET rate variance component was calculated for both environments. Field $=[$ (mean square for genotypes - mean square for error) $\times$ (number of blocks $\times$ number of years)-']. Chamber $=$ [(mean square for genotypes - mean square for error) $\times$ (number of blocks)-'].

Field study. The overall ANOVA for 3 years of ET rate data showed that the genotype and genotype $\mathrm{x}$ year effects were not significant and that the year effect was significant $(P<0.0001)$. Differences in environmental conditions (Table 1) that influence evaporative potential probably accounted for the significant year effect. However, differences in cutting heights between 1985 and the other two years may have contributed to a significant year effect for ET rate. ANOVA for individual years of ET rate data showed that the genotype effect was significant $(P=0.0033)$ only in 1987 (Table 2). ET rates of this study were lower than previously reported rates for the same zoysiagrass species that we used and mowed at cutting heights ranging from 20 to $50 \mathrm{~mm}$ (Biran et al., 1981; Kim and Beard, 1988; Kneebone and Pepper, 1982).

Based on the overall ANOVA for 3 years of LER data, the genotype, year, and genotype $\times$ year effects were significant $(P=$ $0.0006,0.0001$, and 0.0001, respectively). ANOVA for individual years of LER data showed the genotype effect was significant for 1985,1986 , and $1987(P=0.0001$, 0.0098 , and 0.0096 , respectively). Genotypes with the lowest 3-year LER mean included 'PI 231146' and 'Emerald' at 7.5 and $7.6 \mathrm{~mm} \cdot$ day $^{-1}$, respectively, and genotypes with the highest 3-year LER mean included 'Korean Common' and 'El Toro' at 9.5 and $10.0 \mathrm{~mm} \cdot \mathrm{day}^{-1}$, respectively (Table 3 ). This variation in LER among the genotypes would cause different mowing frequency requirements.

Genotype ET rate means were not significantly correlated with genotype LER means in 1985,1987 , or for the three years together; ET rate was significantly correlated $(r=0.61)$ with LER in 1986. There have been several studies evaluating ET rates among turfgrasses maintained under field conditions and using similar methodology. Shearman (1989) reported significant correlations between ET rate and both LER ( $r=$ $0.93)$ and verdure dry weight $(r=-0.89)$ among 12 well-watered perennial ryegrass cultivars. Kim (1983) reported no correlation between ET rate and LER among 10 wellwatered warm-season turfgrass species maintained under uniform cultural conditions in the field. In a second study conducted at the same time, Kim reported a significant correlation $(r=0.78)$ between ET rate and LER among eight well-watered warm-season turfgrass species maintained under field conditions and at their respective optimum cutting heights and $\mathrm{N}$-fertility levels.

Environmental-chamber study. The genotype effect was significant for ET rate, LER, $\mathrm{SHD}, \mathrm{AB}$, and $\mathrm{AD}(P=0.0114,0.0001$, $0.0001,0.0023$, and 0.0003 , respectively). 'KLS-11' and 'Korean Common' ranked lowest for ET rate at 8.4 and $8.5 \mathrm{~mm} \cdot$ day $^{-1}$, respectively, while 'FC-13521' and 'Emerald' ranked highest at 10.1 and 10.3 $\mathrm{mm} \cdot \mathrm{day}^{-1}$ respectively (Table 4$)$. There was no correlation between 3-year genotype ET rate means of the field study and genotype ET rate means of the environmental-chamber study. This result was expected because of different evaporative potentials in the two studies.

ET rates observed under chamber conditions were more than twice those observed under the field conditions during this study. Constant temperature conditions in the chamber were used to create a high evaporative potential. This condition caused greater ET rate variations among genotypes than under field conditions, which were characterized by a lower evaporative potential. The estimated genotype variance components for ET rate under chamber $(0.28)$ and field $(0.04)$ conditions verifies this statement.

Leaf extension rates observed under chamber conditions (Table 4) were less than half those observed under field conditions. This likely was partially due to the lower light intensity of the environmental chamber; PPF of the chamber was $\approx 50 \%$ of full sunlight. 'PI 23521' and 'Emerald' ranked lowest for LER at 1.8 and $2.6 \mathrm{~mm} \cdot \mathrm{day}^{-1}$, respectively, while 'Belair' and 'El Toro' ranked highest at $4.1 \mathrm{~mm} \cdot \mathrm{day}^{\prime}$ for each. There was a significant correlation $(r=0.68)$ between 3-year genotype LER means of the field study and genotype LER means of the environmental-chamber study.

'Emerald' and 'PI 231146' were highest for SHD at 842 and 1552 shoots $/ \mathrm{dm}^{2}$, respectively, while 'Korean Common' and 'Belair' were lowest at 234 and 281 shoots/ din', respectively (Table 4). The AB stomatal densities of 'El Toro' and 'KLS-11' were highest at 345 and 351 stomates $/ \mathrm{mm}^{2}$, respectively, while 'Meyer' and 'KLS-13' were lowest at 279 and 285 stomates $/ \mathrm{mm}^{2}$, respectively. The AD stomatal densities of 'El Toro' and 'PI 231146' ranked highest at 517 and 526 stomates $/ \mathrm{mm}^{2}$, respectively, while '41-21-5' and 'KLS-13' ranked lowest at 407 and 422 stomates $/ \mathrm{mm}^{2}$, respectively. $\mathrm{AB}$ and $\mathrm{AD}$ stomatal densities were similar to densities previously reported for zoysiagrasses (Casnoff et al., 1989).

Genotype ET rate means in the environmental-chamber study were not correlated with genotype means for LER, SHD, AB, or AD. Three-year genotype ET rate means of the field study also were not correlated to genotype means of SHD, AB, or AD. Shearman (1986) reported a significant correlation $(r=0.60)$ between ET rate and verdue dry weight among 20 well-watered Kentucky bluegrass cultivars evaluated in a controlledenvironment chamber maintained at $35 \mathrm{C}$. $\mathrm{AD}$ and $\mathrm{AB}$ have not been reliably associated 
Table 3. Leaf extension rates for 11 zoysiagrass genotypes under field conditions.

\begin{tabular}{lrrrr}
\hline \hline & \multicolumn{4}{c}{$\begin{array}{c}\text { Leaf extension rate } \\
\left(\mathrm{mm} \cdot \text { day }^{-1}\right)\end{array}$} \\
\cline { 2 - 5 } Genotype & 1985 & 1986 & 1987 & Overall \\
\hline PI 231146 & 5.2 & 4.7 & 12.6 & 7.5 \\
Emerald & 5.4 & 4.9 & 12.3 & 7.6 \\
KLS-05 & 5.1 & 6.5 & 11.5 & 7.7 \\
Belair & 6.8 & 8.4 & 10.5 & 8.6 \\
FC-13521 & 6.6 & 6.6 & 13.5 & 8.9 \\
Meyer & 8.1 & 7.2 & 11.5 & 9.0 \\
KLS-13 & 7.3 & 7.6 & 12.1 & 9.0 \\
41-21-5 & 7.3 & 8.1 & 11.8 & 9.1 \\
KLS-11 & 8.2 & 8.7 & 10.9 & 9.3 \\
Korean Common & 10.0 & 7.6 & 10.9 & 9.5 \\
El Toro & 10.8 & 7.1 & 12.1 & 10.0 \\
$\quad$ LSD 0.05 & 2.0 & 2.1 & 1.4 & 1.0 \\
Mean $_{\text {CV }(\%)}$ & 7.3 & 7.0 & 11.8 & 8.7 \\
\hline
\end{tabular}

with ET rate among well-watered turfgrasses (Casnoff et al., 1989; Green et al., 1990).

ET rate variation among 11 morphologically diverse zoysiagrass genotypes maintained under nonlimiting soil moisture was not significant across 3 years of field evaluation. ET rate variation among genotypes was significant under the higher evaporative potential of the environmental chamber. Coefficients of variation in both studies were acceptable (Tables 2 and 4).

One of our aims was to correlate ET rate to a leaf area characteristic (LER) and to a canopy resistance characteristic (SHD) among 11 zoysiagrass genotypes. We did not find the relationship under field or controlled-environment conditions among Zoysia genotypes that other workers have found or suggested among and within other species (Johns et al., 1983; Kim and Beard, 1988; Shearman, 1989); that is, increased leaf area was associated with increased ET rate and increased canopy resistance was associated with decreased ET rate. A critical review of previous reports suggests inconsistent or unexplained observations. ET rate was significantly correlated to LER $(r=0.96)$ at $35 \mathrm{C}$ but not at $25 \mathrm{C}$ among five well-watered Kentucky bluegrasses (Shearman, 1986). Also, SHD was significantly correlated to ET rate at either $35 \mathrm{C}(r=-0.87)$ or $25 \mathrm{C}$ $(r=-0.85)$. ET rate was positively correlated to verdure dry weight among 20 wellwatered Kentucky bluegrasses (Shearman, 1986) and negatively correlated among 12 well-watered perennial ryegrasses (Shearman, 1989). ET rate was significantly correlated to LER among the major warm-season turfgrasses when maintained at nonlimiting

Table 4. Evapotranspiration rates, leaf extenson rates, and morphological characteristics of 11 zoysiagrass genotypes under controlled-environment conditions.

\begin{tabular}{|c|c|c|c|c|c|}
\hline \multirow[b]{2}{*}{ Genotype } & \multirow[b]{2}{*}{$\begin{array}{c}\text { ET rate } \\
\left(\mathrm{mm} \cdot \text { day }^{-1}\right)\end{array}$} & \multirow{2}{*}{$\begin{array}{c}\text { Leaf } \\
\text { extension rate } \\
\left(\mathrm{mm} \cdot \mathrm{day}^{-1}\right)\end{array}$} & \multirow[b]{2}{*}{ No. shoots $/ \mathrm{dm}^{2}$} & \multicolumn{2}{|c|}{ Stomatal density } \\
\hline & & & & $\begin{array}{l}\text { Abaxial } \\
\text { (stoma }\end{array}$ & $\begin{array}{l}\text { Adaxial } \\
\left.\mathrm{s} / \mathrm{mm}^{2}\right)\end{array}$ \\
\hline KLS- 11 & 8.4 & 3.1 & 307 & 351 & 447 \\
\hline Korean Common & 8.5 & 3.5 & 234 & 344 & 467 \\
\hline KLS-05 & 8.7 & 2.9 & $760^{\circ}$ & 295 & 453 \\
\hline Belair & 8.9 & 4.1 & 281 & 316 & 453 \\
\hline $41-21-5$ & 9.0 & 3.6 & 429 & 301 & 407 \\
\hline KLS-13 & 9.4 & 4.0 & 404 & 285 & 422 \\
\hline El Toro & 9.4 & 4.1 & 306 & 345 & 517 \\
\hline PI 231146 & 9.5 & 1.8 & 1552 & 344 & 526 \\
\hline Meyer & 9.9 & 2.7 & 592 & 279 & 451 \\
\hline FC- 13521 & 10.1 & 2.8 & 785 & 291 & 476 \\
\hline Emerald & 10.3 & 2.6 & 842 & 299 & 449 \\
\hline $\operatorname{LSD}_{0.05}$ & 1.0 & 0.5 & 145 & 38 & 42 \\
\hline Mean & 9.3 & 3.2 & 592 & 314 & 461 \\
\hline $\mathrm{CV}(\%)$ & 6.4 & .8 .0 & 13.0 & 6.8 & 5.4 \\
\hline
\end{tabular}

soil moisture and their respective optimum mowing heights and $\mathrm{N}$ fertility rates, but was not correlated when maintained under uniform cultural conditions (Kim, 1983).

The hypothesis that selected morphological traits would influence ET rates of wellwatered turfs of 11 Zoysia genotypes was not supported. This result could be attributed to a narrow range in the integrated canopy morphology resistance for the Zoysia genotypes selected and/or to the complex interactive nature of canopy resistance that may not necessarily be reflected in single-component analyses. More work is needed to evaluate the influence of plant morphology on the ET rate of zoysiagrasses when maintained at soil moisture levels lower than well-watered.

\section{Literature Cited}

Aronson, L. J., A.J. Gold, R.J. Hull, and J.L. Cisar. 1987. Evapotranspiration of cool-season turfgrasses in the humid Northeast. Agron. J. 79:901-905.

Beard, J.B. 1973. Turfgrass: Science and culture. Prentice-Hall, Englewood Cliffs, N.J.

Beard, J.B. 1985. An assessment of water use by turfgrasses, p. 47-60. In: V.A. Gibeault and S.T. Cockerham (eds.). Turfgrass water conservation, Univ. of California, Div. of Agr. and Natural Resources Publ. 21405.

Beard, J.B. 1989. Turfgrass water stress: Drought resistance components, physiological mechanisms, and species-genotype diversity, p. 2328. In: H. Takatoh (cd.). Proc. 6th Intl. Turfgrass Res. Conf., Tokyo, July 1989. Jpn. Soc. Turfgrass Sci.

Biran, I., B. Bravdo, L Bushkin-Harav, and E. Rawitz. 1981. Water consumption and growth rate of 11 turfgrasses as affected by mowing height, irrigation frequency, and soil moisture. Agron. J. 75:85-90

Casnoff, D. M., R.L. Green, and J.B. Beard. 1989. Leaf blade stomatal densities of ten warm-season perennial grasses and their evapotranspiration rates, p. 129-131. In: H. Takatoh (cd.). Proc. 6th Intl. Turfgrass Res. Conf., Tokyo, July 1989. Jpn. Soc. Turfgrass Sci.

Green, R. L., J.B. Beard, and D.M. Casnoff. 1990. Leaf blade stomatal characterizations and evapotranspiration rates of 12 cool-season perennial grasses. HortScience 25:760-761.

Johns, D., J.B. Beard, and C.H.M. van Bavel. 1983. Resistance to evapotranspiration from a St. Augustinegrass turf canopy. Agron. J. 75:419-422.

Kim, K.S. 1983. Comparative evapotranspiration rates of thirteen turfgrasses grown under both nonlimiting soil moisture and progressive water stress conditions. MS Thesis, Texas A\&M Univ., College Station.

Kim, K.S. and J.B. Beard. 1988. Comparative turfgrass evapotranspiration rates and associated plant morphological characteristics. Crop Sci. 28:328-331.

Kneebone, W.R. and I.L. Pepper. 1982. Consumptive water use by sub-irrigated turfgrasses under desert conditions. Agron. J. 74:419423.

Kopec, D. M., R.C. Shearman, and T.P. Riordan. 1988. Evapotranspiration of tall fescue. HortScience 23:300-301.

Rice, J. S., E.M. Glenn, and V.L. Quisenberry. 1979. A rapid method for obtaining leaf impressions in grasses. Agron. J. 71:984-986.

Shearman, R.C. 1986. Kentucky bluegrass cultivar evapotranspiration rates. HortScience 21:455-457.

Shearman, R.C. 1989. Perennial ryegrass cultivar evapotranspiration rates. HortScience 24:767769.

Van Bavel, C. H. M., R. Lascano, and D.R. Wilson. 1978. Water relations of fritted clay. Soil Sci. Soc. Amer. J. 42:657-659. 